C. Susan Weiler; Whitman College

DIALOG: Fostering Early Career Development Across the Aquatic Sciences

\title{
Participant Individuals:
}

Partner Organizations:

American Fisheries Society (AFS): In-kind Support

American Geophysical Union: In-kind Support

Estuarine Research Federation Inc: In-kind Support

Ecological Society of America: In-kind Support

North American Benthological Society: In-kind Support

Phycological Society of America: In-kind Support

International Society of Lim: In-kind Support

Society of Canadian Limnolog: In-kind Support

The Oceanography Society: In-kind Support

Western Society of Naturalists: In-kind Support

\section{Activities and findings:}

\section{Research and Education Activities:}

A total of 447 dissertation abstracts were received for the DIALOG V Program, with 146 individuals applying for the DIALOG V Symposium; 47 were invited and 45 have accepted. This represents a significant increase compared to the DIALOG IV Program in which 221 abstracts were registered and 124 applied for the symposium.

The importance of the dissertation registration service is indicated by the increasing number of individuals who take time to register their dissertation even when they are not interested in applying to the symposium. The number of visits to the webpage has also increased significantly over the years. This also reflects graduate interest in being part of the on-line Dissertation Registry and receiving the weekly electronic DIALOG Newsletter. See http://aslo.org/phd.html for details.

\section{Findings:}

The 447 DIALOG V Program participants were citizens of the following countries: Argentina (4), Australia (12), Austria (2), Bangladish (2), Barbados (1), Belgium (5), Brazil (10), Canada (31), Chile (2), China (5), Columbia (4), Costa Rica (2), Denmark (8), Egypt (1), Finland (2), France (12), Germany (35), Ghana (1), Guatemala (1), Iceland (1), India (9), Indonesia (2), Ireland (3), Israeli (4), Italy (4), Japan (7), Kenya (1), Korea (6), Malaysia (2), Mexico (7), Nepal (1), Netherlands (4), New Zealand (1), Nigeria (1), Norway (2), Portugal (3), Russia (1), Slovenia (1), South Africa (2), Spain (13), Sudan (1), Sweden (10), Switzerland (7), Thailand 
(1), Turkey (3), United Kingdom (17), Uruguay (2), Venezuela (1), Zimbabwe (1) and the United States (188). One did not specify citizenship.

Of the 447 participants for DIALOG V, 229 completed their Ph.D. at U.S. Institutions, compared with 105 for DIALOG IV. Participant $s$ included:

$10(2 \%)$ Atmospheric, global, social and terrestrial

24 ( 5\%) Hydrology

$136(30 \%)$ Limnology

$277(62 \%)$ Oceanography

$198(44 \%)$ Female

$249(56 \%)$ Male

9\% were from U.S. underrepresented minorities.

\section{Training and Development:}

The DIALOG symposium reaches approximately 40 new PI's at a pivotal point in their research careers. Based on their comments, the symposium changes the way participants think, communicate, and approach their research. The science community and the general population will benefit from the perspectives these new PI's bring back to their home institutions and share with their students and colleagues. This group should act as a catalyst to move the entire field in exciting new, interdisciplinary directions.

To reach more graduates, plans are underway to establish the symposium on an annual basis.

By facilitating the development of close collegial ties, symposium participants come away with a network of colleagues from around the globe with interests in aquatic science research and education.

Past participants are collaborating on research proposals, and all have noted that participation has enabled them to develop a more interdisciplinary view of their field, influencing the way they interpret, communicate, and approach their research.

\section{Outreach Activities:}

1. Participants in the DIALOG symposia have been involved in interdisciplinary (including some international) research collaborations; an international student exchange program at two institutions; the organization of several workshops and meeting sessions; and the ongoing communication throughout the entire group about research, education and science policy issues via an electronic distribution list. 
2. The dissertation compilation (available on the web site and compiled into a printed publication after each symposium) has been and is continuing to be used by established scientists, managers and students to get an overview of the latest research and to identify these new entrants to the scientific community..

3. The demographic information is providing a profile of the newest entrants to the aquatic science community--their gender, age, ethnicity, citizenship, Ph.D.-granting institutions and subsequent employers, and disciplinary interests. This information will enable a variety of interest groups to better track the aquatic science community (which has been difficult to profile, due to the large number of degree-granting institutions, departments in which an aquatic scientist might reside, and variety of key words under which aquatic science falls in general science databases).

\section{Journal Publications:}

Weiler, C.S., "DIALOG IV Symposium report: What's up with this new generation of aquatic scientists?", L\&O Bulletin, vol. 10 (4), (2001), p. 72. Published

Burks, R.L., D.R. Corbett, D.M. Gibson, D.L. Hoskins, S.A. Ludsin, K.I. Stocks and C.S. Weiler, "Successful Mentoring: Reflections of recent aquatic science PhDs.", AAAS Next Wave, vol. , (, p. . Submitted

Meysman, F.J.R., "Harry Potter and the Ecologist's Thesaurus.", Frontiers in Ecology and the Environment, vol. , (2003), p. . Submitted

Talley, D.M., E.W. North, A.R. Juhl, D.A. Timothy, D. Conde, J.F.C. deBrouwer, C.A. Brown, L.M. Campbell, T. Garstecki, C.J.

Hall, F.J.R. Meysman, D.M. Nemerson, P.W. Souza Filho and R.J. Wood., "Research challenges at the land/sea interface. Report from the

2004 DIALOG/DIACES symposium.", Estuarine, Coastal and Shelf Science, vol. , (2003), p. . Accepted

Book(s) of other one-time publications(s):

Weiler, C.S., "DIALOG IV: Dissertations Initiative for the Advancement of Limnology and Oceanography." , bibl. , (2003). Book Published

Weiler, C.S., "DIALOG V: Dissertation Initiative for the Advancement of Limnology and Oceanography. Program Report with Ph.D. Dissertation Citations." , bibl. , (2003). Book Published

Weiler, C.S., "DIALOG V: Dissertation Initiative for the Advancement of Limnology and Oceanography. Program Report with dissertation abstracts from American citizens, U.S. degree recipients and U.S. residents." , bibl. , (2003). Book Published

Weiler, C.S., "DIALOG V: Dissertation Initiative for the Advancement of Limnology and Oceanography. Program Report including abstracts from degrees completed outside the U.S." , bibl. , (2003). Book Published

Weiler, C.S., "DIALOG V: Dissertation Initiative for the Advancement of Limnology and Oceanography. Program Report including abstracts from degrees completed outside the U.S." , bibl. , (2003). Book Published

Weiler, C.S., "DIALOG V Program Report. http://marcus.whitman.edu/ weile" , bibl. , (2003). internet Published 
Weiler, C.S., "Talking Tips: Resources for preparing scientific presentations recommended by DIALOG and DISCCRS program participants.

http://marcus. whitman,edu/ weilercs/TalkingTips/" , bibl. , (2003). Book inemet

Baker, A., J. Benoit, R. Burks, M. Castillo, R. Corbett, D. Hoskins, J. Klug, R. Shipe and S.

Wilhelm., "Academic Job Hunting Tips and Advice: Results of DIALOG IV Symposium

Working Group Discussion." , bibl. , (2001). http://aslo.org/phd/jobhuntiing.pdf

Published

Conde, D., A. Ferrara, S. Gerken, M. Julius, J. Martin, C. Natunewicz, D. Nemerson, E. Parnell, J. Warren and D. Zawada., "DIACES 2002 Job Search Strategies and Tips." , bibl. , (2002). http://aslo.org/phd/jobhunting2002.html Published

Karentz, D., "Tips for Proposal Writers. Prepared for DIALOG IV Workshop." , bibl. , (2001). http://aslo.org/phd/proposal.pdf Published

\section{Other Specific Products:}

\section{Internet Dissemination:}

http://aslo.org/phd.html

\section{Contributions:}

\section{Contributions within Discipline:}

The dissertation registry provides a unique introduction to the work of this most recent generation of aquatic scientists. Each year increasing numbers of graduates take advantage of the opportunity to be part of this international collection, and more scientists, employers and administrators use this resource to identify recent graduates and get an overview of their work. Dissertation abstracts are submitted on line and immediately posted on the ASLO web site in a format that can be searched by year, name, and key words (www.aslo.org/phd.html). In addition to the recognition, program participants receive a compilation of abstracts, a directory, and a demographic profile of their cohort. An electronic distribution list keeps recent grads informed about job opportunities, resources, recent advances across the aquatic sciences, and other research and professional news. Finally, the interdisciplinary symposium offers a unique opportunity for grads to get to know each other and share common experiences, and address the challenges and opportunities facing new professionals.

\section{Contributions to Other Disciplines:}

The DIALOG Program is a long-term investment in human resources and science infrastructure. The most interesting and important questions in aquatic and other sciences are increasingly interdisciplinary and this program brings together scientists from across the full spectrum of biologically relevant aquatic science. 
The DIALOG database will become increasingly useful as more graduates participate. While the full impact of the program will probably not be realized for many years, there have already been many tangible results. Several interdisciplinary (including some international) research collaborations have been started; an international student exchange program has been set up at two institutions; several workshops and meeting sessions have been organized; and the entire group continues to communicate about research, education, and science policy issues via an electronic distribution list.

\section{Contributions to Education and Human Resources:}

The goal of the DIALOG symposium is to foster cross-disciplinary and international understanding and interactions at an early career stage, so that interdisciplinary perspectives and collegial relationships can build over a full professional lifetime.

Participants come from a variety of institutions, including some of the most innovative and productive aquatic research programs in the world. The international mix provides valuable insight into the research strengths and concerns in different parts of the globe. Unlike so many professional conferences where multiple concurrent sessions force us to attend narrow sessions on select topics, the DIALOG symposium affords the luxury of listening without distraction to a diverse array of topics, to look for relationships and develop a broader context for their work.

\section{Contributions to Resources for Science and Technology:}

The most interesting and important questions in aquatic and other sciences today are increasingly interdisciplinary. In addition, we find that our scientific community and society as a whole are increasingly global, interdependent, and interactive. Therefore the very concept of the DIALOG program is pertinent and timely as it facilitates the vital exchange of knowledge, ideas, and science that is necessary in this new scientific climate and global community. The symposium, in particular, brings together scientists, at a pivotal point in their research careers, from across the full spectrum of biologically relevant aquatic science, from a variety of scientific backgrounds, from various institutions, and from different countries and cultures. This dynamic mix then participates in an intensive seven-day symposium where all participants gain an overview of the work of the others and are exposed to different ways of thinking about and conducting research. The collegial bonds and lines of communication formed will remain throughout their professional careers to sustain, stimulate, and enhance their work. The scientific community and the general population can only benefit from the perspectives these 'new' scientists bring back to their home institutions (and countries) and then go on to share with their students and colleagues. Based on actual comments from earlier symposium participants we know that the experience significantly changed the way they think, communicate, and approach their research. This group should act as a catalyst to move the entire field in exciting new, interdisciplinary directions that will address the aquatic science issues of the future. The DIALOG program is a long-term investment in human resources and science infrastructure. As it continues and its scope widens, it 
will, directly and indirectly, continue to positively impact the aggregate research community and through that, society in general as we increasingly depend on research results for understanding and managing vital aquatic systems and resources.

\section{Contributions Beyond Science and Engineering:}

1. Participants in earlier DIALOG symposia have been involved in interdisciplinary (including some international) research collaborations; an international student exchange program at two institutions; the organization of several workshops and meeting sessions; and the ongoing communication throughout the entire group about research, education and science policy issues via an electronic distribution list. We have also learned that this core group has expanded as information and insights gained through the program are shared with students, postdoctoral associates, and colleagues.

2. The dissertation compilation (available at www.aslo.org/phd.html and compiled into a printed publication after each symposium) has been and is continuing to be used by journal editors and program officers to identify reviewers; by meeting organizers to identify speakers and session chairs; by scientists and administrators to get an overview of the latest research and to identify potential postdoctoral researchers and job applicants; and by fellow students, researchers, and new entrants to the aquatic science community.

3. The demographic information is providing a profile of the newest entrants to the aquatic science community-their gender, age, ethnicity, citizenship, Ph.D.-granting institutions and subsequent employers, and disciplinary interests. This information should enable a variety of interest groups to better track the aquatic science community (which has been difficult to profile, due to the large number of degree-granting institutions, departments in which an aquatic scientist might reside, and variety of key words under which aquatic science falls in general science databases). 